\title{
EDITORIAL
}

\section{Does traffic-related air pollution contribute to respiratory disease formation in children?}

\author{
M. Jerrett
}

$\mathrm{n}$ the current issue of the European Respiratory Journal, BRAUER et al. [1] report positive associations between markers of traffic-related air pollution and respiratory health outcomes, including asthma onset, incidence of wheeze, ear/nose/throat infections and serious colds or flu, in a large cohort of children 4 yrs of age. This study replicates and extends earlier findings on the same birth cohort at 2 yrs of age. Although a replication, the findings here are more compelling than the earlier study for a number of reasons. First, the effects are larger and more consistent than in the study of the children at 2 yrs of age. In the field of air pollution epidemiology, which closely links to government policy and regulation, concepts such as statistical significance take on a greater meaning, one that often goes beyond what epidemiologists and health scientists consider essential to interpreting results. The stronger and more consistent effects in the current study bolster a growing body of research suggesting that more refined exposure metrics associate with larger respiratory health effects in children, which are discussed hereafter. Secondly, and linked to the first point, the diagnostic accuracy of the conditions after the first 4 yrs of life is likely to be higher than in the first 2 yrs of life, again leading to greater confidence in the association. The relative consistency of the associations at 4 yrs of age compared with those at 2 yrs of age suggests that onset and persistence of respiratory disease formation begins at an early age and continues throughout the course of life. Thirdly, this study uses among the most sophisticated methods for exposure assessment, based on spatially and temporally representative field measurements and land use regression, capable of capturing the small area variation in traffic pollutants. Finally, this study remains one of the few population-based cohort studies operating in the world today that is capable of assessing disease incidence. Another major study, the Children's Health Study [2] in Southern California, USA, focused on older children, aged 5-18 yrs; therefore, the study by BRAUER et al. [1] fills a gap in the literature on early onset.

In examining the contribution of the study by BRAUER et al. [1], it is worth reviewing the current state of knowledge on childhood respiratory disease in relation to air pollution exposures. With the global increase in asthma over the past $30-40 \mathrm{yrs}$, it appears unlikely that the higher rates of

STATEMENT OF INTEREST: None declared.

CORRESPONDENCE: M. Jerrett, Division of Environmental Health Sciences, School of Public Health, University of California, Berkeley, CA 94720-7360, USA. Fax: 1 5106425815. E-mail. jerrett@berkeley.edu prevalence are due to genetic factors alone or to changes in diagnostic prognosis [3]. If one accepts these propositions, some aspect of the environment must be implicated. Both indoor and outdoor air pollutants have been suggested as biologically plausible risk agents but, beyond symptom exacerbation, neither has been definitely linked with asthma onset or with related respiratory outcomes [4].

Complicating this picture is the seeming contradiction between declining levels of regionally distributed air pollutants, such as particles with a $50 \%$ cut-off aerodynamic diameter of $2.5 \mu \mathrm{m}$ (PM2.5), sulphate particles, sulphur dioxide and ozone, over the past 30 yrs concurrent with increasing asthma prevalence. Although regional levels of pollution have decreased, the relative contribution from traffic pollution has increased in many places. A plethora of unmeasured pollutants may actually be increasing near roadways, although this is difficult to assess empirically as field measurements are lacking. Unlike historic environmental exposures that tended to concentrate locally around point sources, major shifts in economic production have given rise to a more equal distribution of pollution across the urban landscape, paradoxically increasing the population exposed to roadways, while overall levels of pollution measured at the central monitor have decreased [5]. Given this temporal alignment of increasing traffic exposures with increasing asthma prevalence, most recent research has concentrated on the role of traffic pollution in the formation of respiratory disease. Such emphasis is supported by toxicology since traffic-related pollutants are enriched with toxicologically active transition metals, polycyclic aromatic hydrocarbons, quinones and ultrafine particles [6], which elicit oxidative stress leading, subsequently, to pro-inflammatory responses in the cardiopulmonary system.

Beyond these overarching issues, current literature on the respiratory health effects of traffic-related information reveals two important shortcomings, both of which are alleviated by BRAUER et al. [1]. The first is exposure misclassification and the second is lack of emphasis on disease incidence [7]. Probably as a result of these limitations, findings linking air pollution specifically to asthma and associated respiratory disease have been inconclusive. Some studies report positive, significant associations between traffic-related exposure and asthma or associated symptoms [8], while others indicate null results [9]. Most of these studies utilised basic measures of distance to roadway as a proxy for exposure and were based on a cross-sectional design.

Due to the small area variation in some particle constituents and in gaseous co-pollutants, field measurements capable of 
capturing variability in air pollutants at the within-community or intra-urban scale are needed to identify the health effects of specific components of the complex urban air pollution mixture. Exposures assigned on distance to traffic or traffic counts near the home are prone to both classical and nondifferential exposure measurement errors that can inflate standard errors and bias the results. BRAUER et al. [1] collected field samples of nitrogen dioxide $\left(\mathrm{NO}_{2}\right), \mathrm{PM} 2.5$ and soot (as indicated by the reflectance on the PM2.5 filters). Using the land use regression method, the authors were able to derive detailed spatial gradients of exposure for $>4,000$ children at key points of gestation and early childhood. The exposure assessment is also supported by two validation studies that indicate good agreement between modelled and personal exposure, evidence that enhances the overall plausibility of the results from this and other studies.

Viewed in the context of other recent findings from the southern California region [10], the more definitive results by BRAUER et al. [1] infer that some of the inconsistency in the earlier findings may have resulted from an over-reliance on crude proxies for exposure. In the Children's Health Study [2], where $\mathrm{NO}_{2}$ levels were measured directly in front of the children's homes, there was a large association between asthma prevalence and this marker for traffic pollution (odds ratio 1.83 ; 95\% confidence interval 1.04-3.22) over the $5.7 \mathrm{ppb}$ interquartile range of exposure. Thus, for both respiratory disease incidence and asthma prevalence, a pattern of more accurate exposure assessment leading to larger reported associations is beginning to be seen.

Regarding the lack of population cohorts for investigating disease incidence, there are very few studies available. Earlier studies have suggested that local traffic pollution may contribute to asthma onset. One cohort study from Japan reported associations between community $\mathrm{NO}_{2}$ measured at a central monitor and asthma incidence [11].

By integrating advanced exposure modelling and longitudinal follow-up, BRAUER et al. [1] have addressed two of the major weaknesses in the current literature. Their work fits into a broader picture of air pollution and health effects throughout the course of life, where there is some indication that exposure during pregnancy affects subsequent respiratory health [12] with effects likely to continue through the first 4 yrs of life, as indicated in the study BRAUER et al. [1], and probably persisting into later childhood [8]. Throughout adolescence, air pollution adversely affects lung function development [10] and then, in later life, these impacts appear to manifest themselves largely through the cardiovascular system, where air pollution may even contribute to atherosclerosis [13] and subsequent death from cardiovascular disease [14].
Although many uncertainties remain, BRAUER et al. [1] have strengthened the evidence base suggesting that air pollution does contribute to respiratory disease formation in children.

\section{REFERENCES}

1 Brauer M, Hoek G, Smit HA, et al. Air pollution and development of asthma, allergy and infections in a birth cohort. Eur Respir J 2007; 29: 879-888.

2 Gauderman WJ, Avol E, Lurmann F, et al. Childhood asthma and exposure to traffic and nitrogen dioxide. Epidemiology 2005; 16: 737-743.

3 Eder W, Ege MJ, von Mutius E. The asthma epidemic. N Engl J Med 2006; 355: 2226-2235.

4 Selgrade MK, Lemanske RF Jr, Gilmour MI, et al. Induction of asthma and the environment: what we know and need to know. Environ Health Perspect 2006; 114: 615-619.

5 Buzzelli M, Jerrett M, Burnett RT, Finkelstein N. Spatiotemporal perspectives on environmental justices in air pollution exposure. Ann Assoc Am Geogr 2003; 93: 557-573.

6 Nel A. Atmosphere. Air pollution-related illness: effects of particles. Science 2005; 308: 804-806.

7 Sarnat JA, Holguin F. Asthma and air quality. Curr Opin Pulm Med 2007; 13: 63-66.

8 McConnell R, Berhane K, Yao L, et al. Traffic, susceptibility, and childhood asthma. Environ Health Perspect 2006; 114: 766-772.

9 Lewis SA, Antoniak M, Venn AJ, et al. Secondhand smoke, dietary fruit intake, road traffic exposures, and the prevalence of asthma: a cross-sectional study in young children. Am J Epidemiol 2005; 161: 406-411.

10 Gauderman WJ, Vora H, McConnell R, et al. Effect of exposure to traffic on lung development from 10 to 18 years of age: a cohort study. Lancet 2007; 369: 571-577.

11 Shima M, Nitta Y, Ando M, Adachi M. Effects of air pollution on the prevalence and incidence of asthma in children. Arch Environ Health 2002; 57: 529-535.

12 Pinkerton KE, Joad JP. Influence of air pollution on respiratory health during perinatal development. Clin Exp Pharmacol Physiol 2006; 33: 269-272.

13 Kunzli N, Jerrett M, Mack WJ, et al. Ambient air pollution and atherosclerosis in Los Angeles. Environ Health Perspect 2005; 113: 201-206.

14 Pope CA 3rd, Burnett R, Thurston GD, et al. Cardiovascular mortality and long-term exposure to particulate air pollution: epidemiological evidence of general pathophysiological pathways of disease. Circulation 2004; 109: 71-77. 